\title{
Sex Offender Characteristics: Analysis Based on a Sample of Hungarian Prisoners
}

\author{
Mihály Somogyvári 8 (D) \\ Hungarian Prison Service Headquarters, Head of Department of Assessment and Methodology; Student of the Doctoral School of \\ Law Enforcement at the National University of Public Service, Hungary \\ $\checkmark$ Corresponding Author: Mihály Somogyvári, E-mail: somogyvari.mihaly@gmail.com
}

\section{ARTICLE INFORMATION \\ Received: February 14, 2021 \\ Accepted: March 21, 2021 \\ Volume: 3 \\ Issue: 3 \\ DOI: $10.32996 /$ jhsss.2021.3.3.6}

\section{KEYWORDS}

Sex offenders, prison, child molesters, rapists

\section{ABSTRACT}

The present study introduces the differences in sex offender groups primarily from the perspective of prison, focusing on the attributes that determine placement, safety, and the conditionality of therapeutic programs. The study is primarily based on the risk analysis and registration database of the Hungarian Prison Service. The result of the study is that perpetrators of sexual abuse against children, and perpetrators of sexual assault against adults showed significant differences in each reintegration needs and in-prison risks, including their background and childhood, in-prison and out-of-prison vulnerability, integration issues, suicide risk, and other areas. Those who abuse children show a unique picture different from all other groups of offenders, while violent sex offenders targeting adults show similarities in most areas to violent offenders in the control group.

\section{Introduction}

Criminological and clinical research on sexual crimes, including the offence, the perpetrators, as well as distinct typologies and therapeutic methods, covers a very wide range (Ward et al., 2006). However, it is important to note that the location of research and therapeutic programs - due to the case of confinement - is typically the prison itself. Consequently, methodological and theoretical research from the perspective of prisons is relevant in two respects.

a. On the one hand, the methodology and results of the research are significantly determined by the fact that the examined target group is in prison or has been released from prison. This is not just a sampling question, but also from the point of view of explaining and interpreting the results, and the effects and peculiarities of the institutional system of imprisonment cannot be ignored.

b. On the other hand, it follows from the above that the framework provided by prisons also significantly determines the possibility and success of therapeutic devices (Day et al., 2012; Blagden et al., 2014; Blagden et al., 2017). Although research to this end is primarily focused on an environment supporting the therapeutic effect, prisons have a primary role in providing a basic framework for placement and conditions, prior to assessing and addressing the needs of the prisoners. Thus, in general, it is also worth examining the characteristics of sex offenders from the point of view of prisons (as a condition), which also provide information relevant to imprisonment.

The main aim of the present study is to provide an applied analysis of the essential differences that can be perceived among sex offenders, particularly in terms of characteristics relevant to imprisonment.

\section{Terminology and definition issues}

Above all, it must be kept in mind that similarly to the majority of inmates, sex offenders are a very heterogeneous group, in legal, criminological and psychological terms, as well.

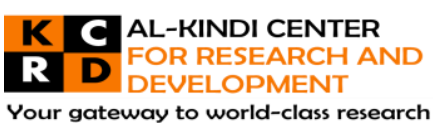

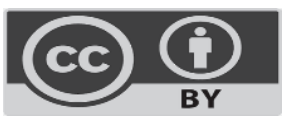

Published by Al-Kindi Center for Research and Development. Copyright (c) the author(s). This open access article is distributed under a Creative Commons Attribution (CC-BY) 4.0 license 
Different sex offender types have significantly different patterns according to victim age, level of acquaintance, level of use of violence, and so on. Much of the literature while referring to "sex offenders" mean child molesters, paedophiles, and rapists, but it should be noted that the terms used actually cover a much wider range and are often misleading without a proper definition.

In the course of conceptual clarification, the most important thing is to state that sex offender - due to its criminal nature - is primarily a legal category (Grady, 2009). This is particularly important in view of the fact that the people included in the research committed a legally sanctioned act on the basis of which they were convicted. So, these are not cases that have been interpreted as purely paraphilic, but which have been defined as a crime with the specific factors of committing it.

The acts classed in this category cover a wide range of behaviours, which may also differ in the legal terminology ${ }^{2}$ of the different countries, and the social perception and danger of each crime may also vary significantly.

From a methodological point of view, the offender's traits also have additional relevance. Extensive theories focusing on the origins of sexual offenses typically examine the issue based on the social and structural background of the offender's behaviour, and from a psychological and psychiatric point of view (Ward et al., 2006), affecting criminal and penitentiary law beyond the field of psychology and medicine. However, regardless of the field of science involved in the study of sex offenders, the research will include subjects who have committed a sanctioned act in some legal sense and may form a common set with people diagnosed with paraphilias in this regard, but are by no means the same.

This is of particular interest from a clinical point of view, especially in case of child molesters ${ }^{3}$. From a methodological point of view, it is a critical issue that child molesters and pedophiles are not the same. Pedophilia in the broadest sense is a sexual paraphilia, which in turn means a sexual attraction, not the sanctioned act itself. It is fundamental professionally that only a fraction of child molesters are pedophiles, as there may be a number of motivations behind sexual acts against young people. Theoretically, pedophilia as a sexual paraphilia is not an active mode of perpetration (Feelgood \& Hoyer, 2008). But regardless of this theoretical basis, studies of paedophilia as paraphilia typically base their analysis on criminal samples (Murray, 2000).

The Council of Europe SPACE-I publications (Aebi et al., 2015-2019) provide the most comprehensive, standard benchmark for European comparisons of the number of prisoners convicted of sexual offenses. In addition to the underlying trends, the analysis of the data also sheds light on the legal terminological difficulties of sexual offenses.

For sexual offenses, SPACE collects two types of data: "Rape" and "Other types of sexual offenses", i.e. perpetrators of sexual violence, and all other perpetrators of sexual offenses. Based on the data, it is important that the two categories cannot be separated in the reporting of several countries, and due to different legal systems, the content of the two categories may also differ from country to country. However, data collected over several years along a similar structure are suitable for demonstrating European trends. Based on the data, it is clear that there is an increasing trend in both categories over the years ${ }^{4}$. This may be due to both changes in practices in judicial decision making and a decrease in latency, or even some social change.

\begin{tabular}{|c|c|c|c|}
\hline & Rape & $\begin{array}{c}\text { Other types of sexual } \\
\text { offence }\end{array}$ & Total \\
\hline \hline 2019 & 5,1 & 5,1 & 10,2 \\
\hline 2018 & 4,6 & 3,9 & 8,5 \\
\hline 2017 & n.d. & n.d. & n.d. \\
\hline 2016 & 4,5 & 3,3 & 7,8 \\
\hline Average: & 3,9 & 3,7 & 7,6 \\
\hline
\end{tabular}

According to the Hungarian register, $6.1 \%$ of the total prisoner population was registered as a sex offender (including all such crimes) in November 2020, together with prisoners who had a final conviction and persons serving pre-trial detention ${ }^{5}$. Based on

\footnotetext{
${ }^{2}$ Based on Hungarian laws, in addition to violent sexual acts, this includes those who run a brothel, but also the procurers (pimps), and those committing incest.

${ }^{3}$ The Hungarian term, child-molesting may be misleading as to the nature of the act; in Hungarian conceptual use, it does not imply a violent, coercive nature, however, Anglo-Saxon literature typically uses the term "child molester" to describe sexual abuse against children. Thus, for the sake of terminological simplification, I use this term in the remainder of the study.

${ }^{4}$ The "Other types of sexual offense" category in 2019 is somewhat distorted by the fact that San Marino's only inmate fell into that category, so that year, $100 \%$ of San Marino inmates fell into that category. Despite the data bias, the trend can be seen.

${ }^{5}$ In Hungary, on the day of the data retrieval, 24 November 2020, the number of persons in final and pre-trial detention was $16,847$.
} 
the SPACE data, the Hungarian population can be considered lower compared to the European ratio, but if we summarize violent sexual crimes according to the Hungarian legal system, it can be corresponded to the European average of the "rape" category of SPACE statistics (see later).

The lower volume of other sexual offenses may be due to higher latency or different judicial decision-making and administrative difficulties regarding legal terms. Thus, data provision usually refers to the typical crime, not to all the crimes committed. That is, if someone has other, more serious crimes (e.g. homicide or human trafficking) in addition to their prostitution-related offenses in the given legal system, they will be included in the crime statistics along the former.

Due to the methodological peculiarities arising from the offender's characteristics, although many studies and many empirical analyses are produced, their comparability and thus their validity are limited. Due to different legal approaches, it is difficult to compare study samples and control groups, which is accompanied by a relatively high latency for sexual offenses, especially compared to other types of offenses (Quackenbush, 2003; Zgoba et al, 2003), which can be significantly influenced by the different legal practices and the social and cultural attitudes of each country.

\section{Data source and methodology of data analysis}

The present analysis is limited to Hungarian data, and it is based on two separate databases. The first is the system registering the data of the prisoner population of the Hungarian Prison Service (Prisoner Basic Register). This database contains the main data related to the prisoners (e.g.: personal data of the inmates, data on their previous detention, main events, rewards, punishments, data related to employment, data necessary for their release, expected time of release, etc.). From this database, the main demographic data was extracted to be used in framing the analysis.

The data presented in the first half of the study (Demographic and Crime Baseline Data) include data on all perpetrators convicted of violent sexual offences (721 individuals), while for comparison, we looked at convicts, not including violent sex offenders $(12,458$ individuals).

The second database that the study is based on is the risk assessment database (Prison Risks), which included the data presented above for 13078 convicts as of November 2020. The risk analysis system used by the Hungarian Prison Service mainly collects data on the offender's criminal history, family background, socio-economic situation, behaviour within the prison, psychological and health status. Risk analysis focuses primarily on collecting data related to risks within prisons (e.g., aggression, substance use, suicide, vulnerability, etc.). The risk analysis system contains objective, registration data (nature of the crime, demographic data, etc.), data and attitudes based on the prisoners' self-reports, and additional information and professional judgments provided by the staff.

The database of more than ten thousand people was structurally narrowed down during the analysis. During the narrowing of the database, only violent male offenders with adult (violent sexual/ rapist) and child (under 14 years of age) victims (child molester) were included in the main study group. Due to the topic, the coherence of the study group, and the conceptual clarification mentioned in the previous chapter, crimes that pertained to only a minimal number of offenders, such as incest, indecency, or prostitution, which can be described as different in nature, was not included. In addition, offenders with victims aged between 14-18 were excluded from the sample. They form a separate legal category in the Hungarian legal system, the incidence of which is relatively low, however, merging it with a group of child victims under 14 or adult victims would be neither methodologically nor terminologically adequate.

Thus, a total of 564 violent sex offenders were included in the sample, out of which 323 had adult victims and 241 of them had victims under the age of 14 . The control group was based on the general group of prisoners, which was divided based on the committed crime into violent / non-violent categories. Approximately a randomized, 5\% of the non-sexual offenders were included in the database, with a total of 557 people (262 non-sexual but violent, 295 non-sexual and non-violent). The resulting database thus contained a total of 1121 people.

It is important to keep in mind that the databases used for the analysis are the extracted data of the registration systems used in the public administration, which were created for practical purposes, therefore the data and variables used in the study were largely given, it was not possible to include new variables. Due to the nature of the databases, essentially categorical variables are available, which were examined by cross-tabulation analysis (applied statistical test: Chi-square test, p <0.05). In the analysis, missing values cover cases where the prisoner did not answer the questions asked. 
All in all, in the analysis, data from two databases are processed.

1. For the presentation of demographic data; the total number of violent sex offenders based on the basic data of the prisoner registry $(\mathrm{N}=721)$

2. During the analysis of risks regarding imprisonment, based on the risk analysis database, we analysed a narrower segment of the above group of prisoners, child molesters $(N=241)$ and rapists $(N=323)$. For comparison, we used a randomized sample of non-sexual but violent $(n=262)$ and non-sexual, non-violent $(n=295)$ prisoners.

\section{Demographic and criminal background data}

The Penal Code of the Hungarian legal system deals with sex offenders in a separate chapter, which covers a wide range. In terms of the types of their crime, their ratio to the total prison population is shown in the following table.

\begin{tabular}{|c|c|}
\hline \multicolumn{2}{|l|}{ Compared to the total population $\%$} \\
\hline Act of violence & 5,4 \\
\hline An act related to prostitution & 0,3 \\
\hline Child pornography & 0,1 \\
\hline Use of child prostitution & 0,1 \\
\hline Non-violent sexual & 0,2 \\
\hline Total & 6,1 \\
\hline
\end{tabular}

The table above shows that the rate of non-violent sexual offences is very low, so, as we wrote in the chapter presenting the database, we excluded these offences from the analysis. This narrowing does not reflect the seriousness or social judgment of the act, the methodological implementation of the analysis merely justifies it.

Demographic data (Table 3) were based on data from all perpetrators convicted of violent sexual offenses (721 individuals), while for comparison, we looked at convicts without violent sex offenders (12,458 individuals).

\begin{tabular}{|l|r|r|r|r|r|}
\hline Category of the convict & $\begin{array}{c}\text { Sex offenders } \\
\text { by type (\%) }\end{array}$ & Male (\%) & Female (\%) & $\begin{array}{c}\text { Average } \\
\text { sentence } \\
\text { duration (month) }\end{array}$ & Average age \\
\hline \hline $\begin{array}{l}\text { Violent sexual (age of } \\
\text { victim: } 18+\text { ) }\end{array}$ & 45,63 & $99,10 \%$ & $0,90 \%$ & 90,95 & 40,9 \\
\hline $\begin{array}{l}\text { Violent sexual (age of } \\
\text { victim: } 14-\text { ) }\end{array}$ & 34,26 & $95,50 \%$ & $4,50 \%$ & 97,88 & 44,2 \\
\hline $\begin{array}{l}\text { Violent sexual (age of } \\
\text { victim: } 18-\text { ) }\end{array}$ & 20,11 & $98,60 \%$ & $1,40 \%$ & 101,94 & 40,8 \\
\hline Violent sexual in total & 100,00 & $97,80 \%$ & $2,20 \%$ & 95,53 & 42,0 \\
\hline \hline Rest of the convicts & & $92,50 \%$ & $7,50 \%$ & 60,25 & 38,6 \\
\hline
\end{tabular}

Based on the data, the vast majority of perpetrators of violent sexual crimes, regardless of the age of the victim, are men (97.8\%), while the proportion of women is negligible (2.2\%). This presumably does not necessarily mean that men can only perpetrate these crimes, but presumably the physical aptitudes and personality traits required for the crime are more likely to be present in men.

In terms of age, they are slightly older (mean 42 years), than the average prisoner population (39 years) while the age of perpetrators of child abuse is significantly higher than average (44 years), while the age of the violent offender is closest to that of the average prisoner population.

The duration of sentencing mostly reflects on the legal order of each country by showing which act correlates to which social and criminal policy judgment. Examining the length of the sentences, it can be seen that the perpetrators of sexual crimes are fundamentally more disadvantaged by Hungarian courts than the average prison population (sexual offenders received an average of 91-97 months imprisonment, while the total prison population received an average of 62 months imprisonment). On average, the Hungarian legal system assigns a longer sentence for perpetrators witch child victims, the social judgment against them is higher, which is also reflected in their inferior position within the prison population. At the same time, it is interesting to 
note that the highest average length of sentences is observed for convicts with victims between the ages of 14 and 18 . Not verified but possible reason for this may be in the legal ratings. Victims under the age of 18 and 14, respectively, can be a qualifying factor in themselves, and by default, convicts with victims under the age of 14 and 18 receive a higher sentence than if the victim is over the age of 18 . However, one conceivable reason is that victims over the age of 14 but under the age of 18 may have more aggravating qualifying factors that are less common for a victim under the age of 14 (group or continuous offense, associated act of violence).

\begin{tabular}{|c|c|c|c|c|c|}
\hline $\begin{array}{c}\text { Educational attainment } \\
\text { /type of crime }\end{array}$ & $\begin{array}{c}\text { Higher } \\
\text { education }\end{array}$ & $\begin{array}{c}\text { High school/secondary } \\
\text { school }\end{array}$ & Skilled worker & $\begin{array}{c}\text { Not more } \\
\text { than } \\
\text { elementary } \\
\text { school }\end{array}$ & $\begin{array}{c}\text { Elementary } \\
\text { school } \\
\text { unfinished }\end{array}$ \\
\hline \hline $\begin{array}{c}\text { Violent sexual (age of } \\
\text { victim: } 18+)\end{array}$ & $2,10 \%$ & $5,20 \%$ & $14,30 \%$ & $61,70 \%$ & $16,70 \%$ \\
\hline $\begin{array}{c}\text { Violent sexual (age of } \\
\text { victim: } 14-\text {-) }\end{array}$ & $2,40 \%$ & $6,90 \%$ & $19,00 \%$ & $59,10 \%$ & $12,60 \%$ \\
\hline $\begin{array}{c}\text { Violent sexual (age pf } \\
\text { victim: } 18-\text {-) }\end{array}$ & 0 & $6,90 \%$ & $13,80 \%$ & $69,70 \%$ & $9,70 \%$ \\
\hline Rest of the convicts & $2,30 \%$ & $8,20 \%$ & $13,10 \%$ & $63,40 \%$ & $13,10 \%$ \\
\hline
\end{tabular}

Based on educational attainment, it can be seen that the most educated group is that of convicts with victims under the age of 14. Education is relevant to socioeconomic status, which matters a lot in the choice of intervention strategies and treatment programs.

The relevance of assessing the demographic differences can be due to the fact that the need for therapy focusing on the nature of crime, and other needs determining its effectiveness arise:

a. On the one hand, effective management of recidivism risks means not only treatment programs for sexual offenses but also logical minimum conditions for social integration. In other words, the more favourable socio-economic situation creates more favourable conditions for the effectiveness of more intensive therapies (even in separate facilities, special programs).

b. On the other hand, the duration of the sentence, the age, the gender distribution determines the framework of the operation of the programs, the conditions of placement, their length, etc.

\section{Risk factors related to imprisonment}

In the remainder of the study, the analysis of the data extracted from the risk assessment database of the Prison Service will be presented. In the analysis, we examined data from violent sex offenders by comparing two larger groups, (offenders with a victim under 14 years of age (child molester) and offenders with a victim over 18 years of age (rapist)), and a randomized average sample of inmates. In the course of the analysis, we examined these two groups of prisoners along two factors that determine the nature and methodology of the treatment programs provided by the correctional facility during imprisonment, as well as the possible directions of placement recommended for each group of offenders. These two major topics are:

a. Deviances in the prisoner's history, their criminality, and the prisoner and their environment criminal involvement and their extent

b. Disciplinary actions and other risks during detention.

The present study does not seek to answer whether juvenile deviances or attitudes in support of crime are determinants of reintegration success or recidivism. The analysis does not intend to go beyond the boundaries provided by prison walls. Basically, the study wants to shed light on what factors may be in consideration of choosing intervention strategies and treatment programs.

\subsection{Criminality, presence of deviances}

The criminality of prisoners fundamentally determines the chances of reintegration, but it is also of great practical relevance within prisons. It determines the security risk, the role of the inmate in the prison hierarchy and the level of self-assertiveness, the direction of the treatment programs that can be provided, and it has an impact on which types of criminals should be placed on 
the same floor or cell. Regarding criminality and the presence of deviances, we examined recidivism, family members' and friends' prison background, juvenile deviances, and drug use prevalence.

\section{Recidivism data}

With regard to the interpretation of recidivism data, it should be noted that the conceptual, legal and methodological approach to recidivism may differ significantly from country to country and in the different researches on the matter at hand. The conceptual difference can be due to whether recidivism means a repeat violation, a crime, or a prison sentence, furthermore, we may see different results regarding the duration of recidivism.

In addition to the above limitations, but with regard to the recidivism rates of sex offenders, several studies have shown that there are significant differences in the types of recidivism and the nature of recidivism (sexual or other offenses), although child molesters generally have more favourable indicators (Hanson \& Bussière, 1998; Langan et al., 2003; Rettenberger et al., 2014; Lussier, 2005). These research results are also supported by the Hungarian data (Table 5), i.e. significant differences can be observed in relation to the recidivism rates of sex offenders, within which the range of data on child molesters can be highlighted.

\begin{tabular}{|c|c|c|c|c|}
\hline & Rapist & Child molester & Violent non-sexual & $\begin{array}{c}\text { Non-violent. non- } \\
\text { sexual }\end{array}$ \\
\hline There is a sentence pending enforcement ${ }^{6}$ & $29,7 \%$ & $19,1 \%$ & $36,3 \%$ & $40,3 \%$ \\
\hline Reoffender ${ }^{7}$ & $43,8 \%$ & $26,6 \%$ & $62,8 \%$ & $58,8 \%$ \\
\hline Has been in prison before the age of 18 & $13,30 \%$ & $2,80 \%$ & $14,70 \%$ & $8,30 \%$ \\
\hline
\end{tabular}

The difference in associated deviances is also well illustrated by the different proportion of ongoing criminal cases. It can be seen that the proportion of sex offenders who still have a sentence pending enforcement is lower overall, but the strongest difference is observed in the group of sex offenders with children as victims, where compared to the average population only half of them is a prisoner with a pending sentence.

Overall, the data show that child molesters have the best data in all respects and violent non-sexual offenders have the least positive values. However, a phenomenon that emerges in connection with a number of variables later on is that data on sex offenders with adult victims tend to be closer to the values of violent non-sexual perpetrators (i.e., non-sex offender groups do not converge towards each other). Thus, even at the beginning of the data analysis, it can be assumed that different types of perpetrators require a significantly different direction of intervention.

\section{Juvenile deviances}

In addition to the legal type variables that characterize recidivism, juvenile deviances also play a key role in determining the extent of recidivism risks, so it is expected that significant differences can be observed between these groups of perpetrators (Table 6).

\begin{tabular}{|c|c|c|c|c|}
\hline & Rapist & Child molester & Violent non-sexual & $\begin{array}{l}\text { Non-violent, non } \\
\text { sexual }\end{array}$ \\
\hline $\begin{array}{l}\text { Alcohol and / or drug use was common before the } \\
\text { age of } 14^{*}\end{array}$ & $10,4 \%$ & $5,2 \%$ & $16,4 \%$ & $9,4 \%$ \\
\hline Between the ages of 14 and 18 , theft was common * & $27,0 \%$ & $13,0 \%$ & $39,5 \%$ & $31,8 \%$ \\
\hline $\begin{array}{l}\text { Between the ages of } 14 \text { and } 18 \text {, fighting was } \\
\text { common }\end{array}$ & $27,8 \%$ & $17,6 \%$ & $34,6 \%$ & $21,9 \%$ \\
\hline $\begin{array}{l}\text { Alcohol and / or drug use was common between the } \\
\text { ages of } 14 \text { and } 18^{*}\end{array}$ & $34,8 \%$ & $23,3 \%$ & $42,1 \%$ & $35,7 \%$ \\
\hline
\end{tabular}

The values of violent but non-sexual convicts showed the highest proportion almost everywhere, but it is important to note that the correlation of the data of rapists and the violent non-sexual control group can be observed only in the case of violent acts,

\footnotetext{
${ }^{6}$ This category includes prisoners who are awaiting a further sentence during their imprisonment, but which have not yet been finalized by a court, so the fact of recidivism and its possible degree are not clear.

${ }^{7}$ A category included in the Hungarian Penal Code and defined by the Court.
} 
for deviances of a non-violent nature (theft, drug use) the data of violent sex offenders are closer to the non-violent offenders of the control group (marked with * in the table). Among the data, the values of child molesters were the most favourable in this case as well.

\section{Background, social relations}

In addition to recidivism and juvenile deviance, other factors in criminality (Table 7) show similar trends. Having lived in state care and correctional institutions is basically low for all groups examined, but presumably higher than the value measured in civil society. However, data on both state care and juvenile detention centre upbringing are interesting.

\begin{tabular}{|c|c|c|c|c|}
\hline & Rapist & Child molester & Sexual non-violent & $\begin{array}{l}\text { Non-sexual, non- } \\
\text { violent }\end{array}$ \\
\hline Have been in juvenile detention centre & $16,3 \%$ & $9,7 \%$ & $21,0 \%$ & $9,3 \%$ \\
\hline Friends in correctional institutions & $38,9 \%$ & $21,4 \%$ & $45,3 \%$ & $40,4 \%$ \\
\hline $\begin{array}{l}\text { Close relatives in correctional } \\
\text { institutions }\end{array}$ & $41,0 \%$ & $30,9 \%$ & $51,8 \%$ & $34,0 \%$ \\
\hline
\end{tabular}

The biggest difference between juvenile detention centres and state care is in opposition to the law and the appearance of acts of violence in youth. Someone gets into state care when there are problems with their family background or their behaviour, i.e. the quality of upbringing, abuse, endangerment, death, or minor behavioural problems. However, a juvenile detention centre is an institution involving deprivation of liberty for juveniles who have committed a crime, but their violation of the law does not reach the level for which, considering their juvenile age and correctability, the court would impose a custodial sentence.

In relation to the data, it should be noted that state care is more common in both groups of sex offenders than in the control groups. As we wrote earlier, state care background assumes to a greater extent that these inmates were themselves victims as children (not necessarily of sexual acts); however, in order to gain a deeper understanding of the phenomenon, the link between state care and violent sexual deviance may be worth exploring.

The table also includes whether the offenders' close relatives or friends have been to prison, or other correctional facilities, which can be interesting in several ways:

a. The role of supportive relationship with friends and relatives is crucial in post-release social integration (Berg $\&$ Huebner, 2011). But as much as the protective role of family and friends is strong and prominent, it is as dangerous and counterproductive when family and friends have high criminality.

b. Related to this is that for those who have had friends and family in prison their status in the prison hierarchy can increase, the presence or absence of which carries (albeit differently) security risks.

c. In case of sex offenders, it is difficult to interpret the family as a protective factor, as the nature of the crime often makes the family abandon them, which often occurs in child molesters, especially if the victim is their own child or one they fostered.

The data show that among sex offenders, offenders against child victims are markedly different from all the other groups, with both friends and family being significantly less likely to be in prison, while drug use is decidedly insignificant. As mentioned above, a non-criminal social environment, if any, can also play a supportive role after release, but the offender's status can be easily predestined to low and vulnerable within the prison, especially in conjunction with the strong condemnation of the crime.

Overall, in addition to demographic data, we see significant differences in the extent of criminality and criminal life paths in the perpetrators and their social environment. This in itself may be decisive in the choice of reintegration tools, but it is also necessary to consider other risks associated with imprisonment, which also determine treatment options within prisons.

\subsection{Risks during detention}

Given the nature of the risks involved in incarceration, they are criminogenic factors that will be relevant to the operation of prisons by identifying security risks (e.g., escape, aggression) and special treatment needs (e.g., suicidal risk). These factors fundamentally determine the treatment of prisoners and their placement (for example, what type of prison, what regime they are placed in). Hereinafter, we focus on three main areas: 
a. suicides and, in this context, adaptability and self-assertion,

b. cooperation and, depending on that, the disciplinary situation,

c. and the risk of victimization.

Risk of suicide, victimization and adaptation

With regard to suicidal risks, there are two fundamentally different circles of self-harm to prisoners, which should be separated in the records and later in the analysis: self-harm and suicide attempt. Attempt at suicide is made with an actual intent to die, while self-harm does not necessarily act with an actual intent to die, and can often be due to relieving tension and dealing with problems in prison (e.g., manipulative for situational gain). The manipulative nature of inmates attempting suicide in prisons has been examined in several studies, suggesting that most of them can be considered manipulative or an attempt to escape incarceration, which can also be considered manipulative from the prison's point of view (Dear et al, 2000; Smith et al, 2019; Haycock, 1989).

\begin{tabular}{|l|c|c||c|c|}
\hline & Rapist & Child molester & $\begin{array}{c}\text { Violent non- } \\
\text { sexual }\end{array}$ & $\begin{array}{c}\text { Non-sexual, non- } \\
\text { violent }\end{array}$ \\
\hline \hline Suicide attempt & $6,4 \%$ & $13,9 \%$ & $11,2 \%$ & $4,8 \%$ \\
\hline Intentional self-harm & $12,0 \%$ & $9,8 \%$ & $16,7 \%$ & $10,4 \%$ \\
\hline Both & $8,4 \%$ & $3,1 \%$ & $9,3 \%$ & $4,3 \%$ \\
\hline Neither & $73,1 \%$ & $73,2 \%$ & $62,8 \%$ & $80,5 \%$ \\
\hline
\end{tabular}

Examining the Hungarian data shows that the highest risk of suicide with real intent to die was in child molesters, while intentional, mostly manipulative self-harm was highest in a population that is sexually violent against adults and violent in other crimes (Table 8). This type of self-harm is less common among sex offenders who have child victims. However, the values are similar to that of a previous analysis in a Hungarian sample (Drexler, 2016), according to which the highest suicide risk (22\%) was characteristic of sex offenders who committed their act against a child in their care.

International studies have found similar differences in suicide risk for each group of sex offenders (Pritchard \& King, 2005), while some studies have shown the opposite, i.e., offenders with adult victims had higher values (Webb et al, 2012). , while others found no difference between groups at all (Jeglic et al, 2012). The discrepancy can be attributed to two main reasons:

a. There may be significant differences in the different methodologies used to collect data on suicides (e.g. self-reports or real medical reports). In the present study, the available data are based on self-reports, while the research of Jeglic et al. was based on documented reports (Jeglic et al, 2012).

b. Another possible reason for the contradiction is not methodological, but institutional, i.e. the manipulative aspect. Selfharm may largely depend on the extent to which the prisoners use it to get what they want and how "accepted"/effective it is by the given institution. However, this also depends significantly on the suicide strategy used in each country (if it is not suitable for enforcing their desires but is considered a disciplinary act, the numbers are likely to be lower).

It can also be seen from the above that the suicidal characteristics of sex offenders have been the subject of several studies, the relevance and hypothesis of which was partly due to the victimological risk of the target group. However, the institutional background influencing the possibility of manipulative behaviour as an analytical aspect or determining variable is typically not examined.

From an applied point of view, however, monitoring suicide data is a priority for prisons. On the one hand, suicide is a prison incident in itself, but exploring the underlying causes is also a primary security aspect, especially if the suicide is not due to psychological lability or a simple manipulative act, but is due to abuse or possibly blackmail.

Closely related to this is whether the prisoners in the study have prison routine, accordingly how well their coping strategies adapt to their situation, and whether they have become victims during their previous incarceration if they had any (Table 9). 


\begin{tabular}{|c|c|c|c|c|}
\hline & Rapist & Child molester & $\begin{array}{c}\text { Violent, non- } \\
\text { sexual }\end{array}$ & $\begin{array}{c}\text { non-sexual, non- } \\
\text { violent }\end{array}$ \\
\hline Have they been a victim in prison & $15,3 \%$ & $22,3 \%$ & $14,7 \%$ & $10,2 \%$ \\
\hline $\begin{array}{l}\text { They are at risk, weak, does not have a prison routine, } \\
\text { so they may have integration problems }\left(^{*}\right. \\
\text { Psychological opinion) }\end{array}$ & $11,5 \%$ & $24,1 \%$ & $1,1 \%$ & $2,4 \%$ \\
\hline
\end{tabular}

Whether a prisoner has become a victim in prison is based on self-reports in Hungary, similarly to acts of self-harm, so the answers given should also be treated with reservation; latency is presumably higher on this issue as well, not only for sex offenders but for the entire inmate population. However, even with this clause, the data show that among perpetrators of sexual offences against a child, there is a significantly higher (nearly double) number of victims of some type within the prison walls.

Self-assertion can also have a major impact on a prisoner's ability to adapt, the direction of their risk within the prison, the likelihood of becoming a victim, and thus the susceptibility to suicide (Table 10).

\begin{tabular}{|l|c|c||c|c|}
\hline \multicolumn{3}{|c|}{ If they had to defend themselves against fellow prisoners, how did they resolve the situation? } \\
\hline \hline & Rapist & Child molester & $\begin{array}{c}\text { Violent, non- } \\
\text { sexual }\end{array}$ & $\begin{array}{c}\text { Non-sexual, } \\
\text { non-violent }\end{array}$ \\
\hline \hline Negotiation & $34,10 \%$ & $29,20 \%$ & $17,90 \%$ & $28,30 \%$ \\
\hline Verbal or physical aggression & $46,30 \%$ & $24,60 \%$ & $66,70 \%$ & $51,70 \%$ \\
\hline Reported the case to a member of staff & $9,80 \%$ & $24,60 \%$ & $9,00 \%$ & $10,00 \%$ \\
\hline Couldn't solve the situation or escaped & $9,80 \%$ & $21,50 \%$ & $6,40 \%$ & $10,00 \%$ \\
\hline
\end{tabular}

Data from the studied inmates show that verbal or physical aggression is fundamentally high within the prison as a problemsolving method, especially for violent offenders in the control group. In disputes, calling for help from staff is generally less common for prisoners; this "form of coping" is most characteristic of perpetrators of sexual acts against children. In their case, it can be seen that different types of self-assertion techniques are used in almost equal proportions, which also shows that negative or inadequate responses, such as asking for external help or escaping the situation, are typical alternatives for them.

\section{Cooperation, disciplinary situation}

The willingness of prisoners to cooperate, the systems set up for this purpose, and the definition and nature of disciplinary acts are presumably different in each country and often adapted to the specifics of the given prison system. In the execution of a prisoner's sentence, there is a serious risk that convicts will not be able, or do not want to comply with internal regulations, do not consider it applicable to themselves. These behaviours and acts typically involve sanction and a disciplinary event. Such an act is when the prisoner intentionally violates or endangers the order and safety of the sentence's execution. Nevertheless, disciplinary acts tend to cover lower levels of deviance, which typically do not reach the level of crime. Overall, therefore, punishment can be obtained for a wide range of smaller-scale acts, so it occurs in the majority of prisoners, and there was no significant difference between the groups in the incidence of punishments alone. Behavioural attitudes towards staff, on the other hand, imply significant differences.

Explicit violent behaviour against staff is very rare (and presumably rarely results "only" in disciplinary acts, they are rather considered as a criminal act that is judged outside the framework of the prison), so it did not reach the limit of the analysis, cases typically remain at the level of verbal aggression. However, there are visible differences between the groups, so it is worth further investigation.

In addition to the punishments, the prisoner's risk of imprisonment and her willingness to cooperate are also described by the high security risk classification and the strict regime category.

The regime in the Hungarian legal system shows the level of co-operation (by default, the prisoner is placed in the medium regime as a starting point, then in case of good behaviour it can be light, in case of bad behaviour it is strict), while the security category is intended to assess the risks posed to the prison's order. Both are based on several aspects and the final decision is made by a board and they paint an accurate picture of the danger the prisoner poses - from the point of view of the prison - and point to significant differences between the groups examined (Table 11). 


\begin{tabular}{|c|c|c|c|c|}
\hline & Rapist & Child molester & Violent non-sexual & $\begin{array}{l}\text { Non-sexual, non- } \\
\text { violent }\end{array}$ \\
\hline $\begin{array}{l}\text { Punishment for disrespectful treatment of } \\
\text { staff }\end{array}$ & $14,8 \%$ & $5,7 \%$ & $14,5 \%$ & $9,5 \%$ \\
\hline High security risk classification & $10,5 \%$ & $7,9 \%$ & $13,4 \%$ & $5,8 \%$ \\
\hline Strict regime & $15,5 \%$ & $5,0 \%$ & $17,9 \%$ & $8,3 \%$ \\
\hline
\end{tabular}

As for sex offenders, an important result is that perpetrators of adult and child sexual abuse are different regarding this variable in the analysis, and the perpetrators against adults is more similar to the violent non-sexual perpetrators in the control group. Offenders of child sexual abuse have the lowest rates of prisoners with punishment, as well as those under strict regimes. The proportion of those classified as high security risk, on the other hand, is slightly higher $(7.9 \%$, compared to the $5.8 \%$ for nonviolent members of the control group), although their security risk is increased by their vulnerability, the high level of victimization described earlier, which should be distinguished from other types of prison risk characteristics (e.g. violence, drug use, disciplinary acts, etc.).

Although the existence of the risks presented above is related to the nature of the act committed by the prisoner, the response to these risks is not necessarily related to the method of treatment that can be linked to the crime. That is, child molesters will have a high risk of victimization due to the victim being a child, however, sex offender therapy is not primarily responding to this, yet it is important to see the risks of detention (e.g. abuse) within each group in order to develop appropriate placement and treatment strategies. From a practical point of view, it is crucial that the group of child molesters is a stigmatized and victimized high-risk group at the bottom of the prison hierarchy (Schwaebe, 2005). This type of offender is considered to be the most morally negative group, both by the wider society, by the prisoners and the staff as well (van den Berg et al, 2017; Greineder, 2013; Higgins \& Ireland, 2009; McNaughton \& Webster, 2018). ; Ricciardelli \& Moir, 2013).

\section{Placement options}

Issues of placement of sex offenders require a serious professional decision. In connection with the decision and the therapeutic goals and their effectiveness, the prison management should consider the use of resources (e.g. staff, infrastructure), the degree of overcrowding, etc. An important aspect is who the focus should be on, what kind of resources should be used to create the special departments (i.e. whether there is a theoretical possibility for a separate department, whether there are enough specialists, etc.) methodology should be followed during the placement.

\section{Separate or combined placement}

Placement is important from the point of view of treatment and prison risks, and in its practical implementation there are two main alternatives: more or less separate and integrated placement.

The advantage of segregated accommodation is safety and a calm environment, as well as peer support that is important for therapy. Its disadvantage is that it also makes it clear to the wider prison environment that the prisoners placed there are sex offenders. This may be a concern in connection with getting out of the unit or coming into contact with other inmates (McNaughton \& Webster, 2018). However, it is not incidental to prison management that segregated placement reduces the likelihood of violence against child molesters who are at the bottom of the prisoner hierarchy.

Although placement is decisive in relation to treatment, research on therapeutic efficacy typically does not focus on the medium in which the therapy is performed (in a dedicated treatment centre, in a psychiatric institution, or in a general prison regime where the sex offender program is only one program among others). Although studies specifically addressing this issue (Day et al., 2012; Blagden et al., 2017) have shown that the institution's supportive climate for therapy is a very dominant factor.

\section{Deductibility - denial of the act - coercion and voluntariness}

An important issue for the development of treatment strategies, but especially for the development of therapeutic programs, is the issue of inclusion or involvement in programs, which raises two key aspects:

a. admitting the offence as a precondition for inclusion in treatment programs,

b. and in this context, the issue of volunteering / coercion in relation to involvement in programs.

Denial of crime can range widely, including relativizing the act, shifting responsibility, or even total denial, non-recognition of the crime (Maletzky, 1996). There can be many factors behind denial, whether it is real innocence or a number of psychological 
aspects that are essentially targeted by sex offender therapies. From a practical point of view, however, it is important to distinguish the shifting of responsibility or the relativization of the act (as cognitive distortions associated with the act) from other causes of denial related to the prison environment.

For sex offenders, cognitive biases are attitudes that transcend the framework of generally accepted rationality and that are related to the background of sexual offences and the maintenance of offender behaviour. Cognitive biases have been most commonly identified as a justifying factor whose function is to reduce cognitive dissonance between deviant sexual act and socially accepted behaviours (Ward, 2000; Ó Ciardha \& Ward, 2012). Cognitive biases related to the relativization of the act and the shift of responsibility also form the basis of further theoretical models, typologies, and treatment systems (Ward, 2000; Polaschek \& Ward, 2002; Gannon \& Polaschek, 2006; Ó Ciardha \& Ward, 2012).

However, an important practical aspect of the issue is that denial is not merely an internal psychological issue, but also a coping strategy within the prison, which is primarily a response to the already cited victimization risk (Schwaebe, 2005). Some research estimates the rate of denial among sex offenders at about 60\% (Maletzky, 1996; Abracen \& Looman, 2004). Based on the analysis containing Hungarian data it can be seen as well that sex offenders typically deny their crimes (Table 12).

\begin{tabular}{|c|c|c|c|c|}
\hline & Rapist & Child molester & $\begin{array}{c}\text { Violent, non- } \\
\text { sexual }\end{array}$ & $\begin{array}{c}\text { Non-sexual, non- } \\
\text { violent }\end{array}$ \\
\hline Consider it exaggerated & $76,20 \%$ & $77,30 \%$ & $63,50 \%$ & $48,30 \%$ \\
\hline Consider themselves innocent & $31,10 \%$ & $50,60 \%$ & $16,10 \%$ & $35,50 \%$ \\
\hline Admit to certain crimes, denies others & $31,10 \%$ & $19,80 \%$ & $29,60 \%$ & $19,90 \%$ \\
\hline Confess to all crimes & $37,90 \%$ & $29,70 \%$ & $54,30 \%$ & $44,50 \%$ \\
\hline
\end{tabular}

Clear admission of the crime is most characteristic of violent offenders in the control group, while it is least common of child molesters. At the same time, the sentence is typically perceived as exaggerated by all groups of prisoners, but this response is particularly prevalent among sex offenders, specifically perpetrators of child sexual abuse.

Confession of the offence is of paramount importance from the point of view of therapeutic methodology (Maletzky, 1996), it is often a condition of involvement or retention in programs, and on the other hand, the dynamics of a group therapy are destroyed by resistance (Schlank \& Shaw, 1996). Thus, high levels of denial also reduce therapeutic involvement and efficacy (Maletzky, 1996).

An important dilemma in this regard is the compulsory nature of therapy. If made mandatory, or if there are severe sanctions for non-cooperation in a therapeutic program (it can directly or indirectly affect parole, for example), cooperation and confession are more likely to be illusory and interest-driven, which may interfere with therapeutic goals.

Of course, the weight of sanctions behind coercion is also an important factor in relation to the issue of coercion and therapeutic efficacy. According to some research, coercion applied in connection with sexual offence programs as a whole does not necessarily have a negative effect, in fact, it facilitates involvement and sticking to the program, thus promoting and strengthening the therapeutic effect over time (Burdon \& Gallagher, 2002). Potential dysfunctions of the effect of coercion may be offset by programs that precede sex offender therapy, the essence of which is for the perpetrator to confess and accept their crime (Schlank \& Shaw, 1996).

\section{Hungarian practice}

The Hungarian Penal Code prescribes a special risk management program for convicts who commit sexual offenses to the detriment of a person under the age of eighteen. Under the relevant regulations, the treatment of sex offenders within the prison service since 2015 has two main professional directions.

One of the treatment options, regardless of the age of the victim, is a series of sessions available for all prisoners at the institute by psychologists working there. Under internal regulations, sex offenders must declare whether they wish to participate in a series of sessions that reduce the likelihood of recidivism. The aim of the sessions and reduce the risk of recidivism are to highlight their responsibilities and correct their criminal attitudes and thinking. Sessions should be scheduled for a minimum of 10 sessions, but the number of sessions should always be tailored to the inmates' needs and requirements, which may exceed 10 sessions. 
The other treatment option is a therapeutic program of at least 8 months available to offenders with victims under the age of 18 , which currently operates in only one prison. Participation in the program is conditional on at least taking partial responsibility for the crime, the ability to work in a group (i.e., to be able to work with others in a psychological sense), and a certain intellectual level, as the program consists mostly of cognitive-behavioural therapy elements, the understanding of which is necessary for its effectiveness.

The central therapy program of at least 8 months offered to sex offenders therefore provides voluntary and segregated placement. The professional supervision of the department is the responsibility of the organizational unit, which also performs and supervises the risk assessment and treatment of the inmate, thus ensuring both the coherence of the data and the synthesis of analysis and treatment. The unit also has several positive outcomes for the perpetrators, mostly due to the risk of victimization and the intensive therapeutic effect. In Hungary this segregated placement concerns the child molesters, based in part on the significant differences presented in the study.

Examining the issue of volunteering and mandatory nature, the Hungarian practice, therefore, voted in favour of volunteering in order to facilitate involvement. Mandatory nature would be particularly feasible if the court decision were to address the mandatory nature of the program and if segregated accommodation could be provided for the entire period of imprisonment. In this case, the actual program could be preceded by the preparatory, sensitizing phase used in the international practice already cited, which would be aimed at resolving the denial.

\section{Conclusion}

The present analysis sought to approach the characteristics of sex offenders from the perspective of prisons, primarily from an applied perspective. Based on the experience of the study, it is useful to draw attention to three main methodological issues.

a. In connection with the analysis and research on sex offenders, a methodological problem that is difficult to overcome is that the content of the legal categories used by each country may differ significantly, either in relation to the age difference of the victim or the nature of physical violence.

b. Another important methodological problem of a legal nature is that prison statistical records are based on a typical crime, which also causes a "record latency", especially in cases where the sexual crime is "covered" by a more serious associated crime.

c. Social science research tries to increase the validity of the results primarily with research methodological tools, typically narrowing research samples and statistical procedures. However, the role of the prison as an environment must be taken into account when studying offenders (especially if the prison population mainly provides the sample), which will result in significant differences between groups of prisoners due to different infrastructures and internal regulatory frameworks.

This analysis covered this in more detail in relation to suicides. That is, the contradictory research results may be due to methodological differences and different penitentiary practices that reinforce or even limit the manipulative nature of self-harm. The suggestion that the operational nature of prisons (as a background determining results) cannot be ignored in the interpretation of research results could equally arise with regard to victimization or therapeutic efficacy, and so on.

Based on the processing of the risk analysis data in Hungary, rapists and child molesters seem to be more different, and the perpetrators with adult victims are more similar to the violent, but non-sexual perpetrators in the control group. That is, it is not appropriate to merge the two categories, either from a management point of view or from the point of view of prison enforcement. They have different attributes in terms of both reintegration needs and in-prison risks, suggesting that one is more predatory and the other is more of a victim. The groups' conclusion is that the similarity is mostly given by the violent nature of the act and not by the sexual motive.

There were also significant differences between the two groups in terms of family and friends' criminality, recidivism, juvenile deviance, drug use, in-prison coping strategies, prison adaptation, and in-prison disciplinary status. In general, perpetrators of child sexual abuse typically have a more balanced background and youth in terms of crime (family and friends have not been in prison, no drug use or juvenile violence), but it is not uncommon for them to be victims before their prison years or to attempt suicide. While among perpetrators of sexual acts against adults, aggression and violence is much more dominant, with the broad array of criminal offenses and almost exclusively manipulative self-harm, with no intention of dying.

These main differences define the segregation of sex offenders on a basic level, their completely different needs and treatment options, which are worth keeping in mind in all countries' reintegration practices. 


\section{References}

[1] Abracen, J., \& Looman, J. (2004). Issues in the treatment of sexual offenders. Aggression and Violent Behavior, 9(3), $229-246$.

[2] Aebi, M. F., Tiago, M. M. \& Burkhardt, C. (2016). SPACEI - Council of Europe Annual Penal Statistics: Prison populations. Survey 2015. Strasbourg: Council of Europe

[3] Aebi, M. F., Tiago, M.M., Berger-Kolopp, L. \& Burkhardt, C. (2017). SPACE I-Council of Europe Annual Penal Statistics: Prison populations. Survey 2016. Strasbourg: Council of Europe

[4] Aebi, M. F., \& Tiago, M. M. (2018). SPACE I - 2018 - Council of Europe Annual Penal Statistics: Prison populations. Strasbourg: Council of Europe

[5] Aebi, M. F., \& Tiago, M. M. (2020). SPACE I - 2019 - Council of Europe Annual Penal Statistics: Prison populations. Strasbourg: Council of Europe

[6] Berg, M. T., \& Huebner, B. M. (2011). Reentry and the Ties that Bind: An Examination of Social Ties, Employment, and Recidivism. Justice Quarterly, 28(2), 382-410.

[7] van den Berg, C., Beijersbergen, K., Nieuwbeerta, P., \& Dirkzwager, A. (2017). Sex Offenders in Prison: Are They Socially Isolated? Sexual Abuse: A Journal of Research and Treatment, 30(7) 828-845.

[8] Blagden, N., Perrin, C., Smith, S., Gleeson, F., \& Gillies, L. (2017). "A different world" exploring and understanding the climate of a recently re-rolled sexual offender prison. Journal of Sexual Aggression, 23(2), 151-166.

[9] Blagden, N., Winder, B., \& Hames, C. (2014). "They Treat Us Like Human Beings"—Experiencing a Therapeutic Sex Offenders Prison. International Journal of Offender Therapy and Comparative Criminology, 60(4), 371-396.

[10] Burdon, W. M., \& Gallagher, C. A. (2002). Coercion and Sex Offenders. Criminal Justice and Behavior, 29(1), 87-109.

[11] Ó Ciardha, C., \& Ward, T. (2012). Theories of Cognitive Distortions in Sexual Offending. Trauma, Violence, \& Abuse, 14(1), 5-21.

[12] Day, A., Casey, S., Vess, J., \& Huisy, G. (2012). Assessing the Therapeutic Climate of Prisons. Criminal Justice and Behavior, 39(2), 156-168.

[13] Dear, G. E., Thomson, D. M., \& Hills, A. M. (2000). Self-Harm in Prison. Criminal Justice and Behavior, 27(2), 160-175.

[14] Drexler, B. (2015) Featured data for sexual offenders. In. Somogyvari M. (Ed.) Review of Hungarian Prison Statistics (pp. 27-37). Budapest, Hungarian Prison Service Headquarters.

[15] Feelgood, S., \& Hoyer, J. (2008). Child molester or paedophile? Sociolegal versus psychopathological classification of sexual offenders against children. Journal of Sexual Aggression, 14(1), 33-43.

[16] Gannon, T. A., \& Polaschek, D. L. L. (2006). Cognitive distortions in child molesters: A re-examination of key theories and research. Clinical Psychology Review, 26(8), 1000-1019.

[17] Grady, M. D. (2009). Sex Offenders Part I: Theories and Models of Etiology, Assessment, and Intervention. Social Work in Mental Health, 7(4), 353-371.

[18] Greineder, Brian (2013). Correctional Officers' Perceptions of Sexual Offenders in the United States: A Qualitative Analysis. International Journal of Criminal Justice Sciences, 8 (1), 24-35.

[19] Hanson, R. K., \& Bussière, M. T. (1998). Predicting relapse: A meta-analysis of sexual offender recidivism studies. Journal of Consulting and Clinical Psychology, 66(2), 348-362.

[20] Haycock, J. (1989). Manipulation and suicide attempts in jails and prisons. Psychiatric Quarterly, 60(1), 85-98.

[21] Higgins, C., \& Ireland, C. (2009). Attitudes towards male and female sex offenders: a comparison of forensic staff, prison officers and the general public in Northern Ireland. The British Journal of Forensic Practice, 11(1), 14-19.

[22] Jeglic, E. L., Spada, A., \& Mercado, C. C. (2012). An Examination of Suicide Attempts Among Incarcerated Sex Offenders. Sexual Abuse: $A$ Journal of Research and Treatment, 25(1), 21-40.

[23] Langan, P. A., Smith, E. L., Durose, M. R., \& United States. Bureau Of Justice Statistics. (2003). Recidivism of sex offenders released from prison in 1994. U.S. Department Of Justice, Office Of Justice Programs, Bureau Of Justice Statistics.

[24] Lussier, P. (2005). The Criminal Activity of Sexual Offenders in Adulthood: Revisiting the Specialization Debate. Sexual Abuse: A Journal of Research and Treatment, 17(3), 269-292.

[25] Maletzky, B. M. (1996). Denial of Treatment or Treatment of Denial? Sexual Abuse: A Journal of Research and Treatment, 8(1), 1-5.

[26] McNaughton, Nicholls C., Webster S. (2018). The separated location of prisoners with sexual convictions: Research on the benefits and risks. Analytical Summary 2018, Her Majesty's Prison and Probation Service

[27] Murray, J. B. (2000). Psychological Profile of Pedophiles and Child Molesters. The Journal of Psychology, 134(2), $211-224$.

[28] Polaschek, D. L. L., \& Ward, T. (2002). The implicit theories of potential rapists. Aggression and Violent Behavior, 7(4), 385-406.

[29] Pritchard, C., \& King, E. (2005). Differential Suicide Rates in Typologies of Child Sex Offenders in a 6-year Consecutive Cohort of Male Suicides. Archives of Suicide Research, 9(1), 35-43.

[30] Quackenbush, R. E. (2003). The Role of Theory in the Assessment of Sex Offenders. Journal of Child Sexual Abuse, 12(3-4), 77-102.

[31] Rettenberger, M., Briken, P., Turner, D., \& Eher, R. (2014). Sexual Offender Recidivism Among a Population-Based Prison Sample. International Journal of Offender Therapy and Comparative Criminology, 59(4), 424-444.

[32] Ricciardelli, R., \& Moir, M. (2013). Stigmatized among the Stigmatized: Sex Offenders in Canadian Penitentiaries. Canadian Journal of Criminology and Criminal Justice, 55(3), 353-386.

[33] Schlank, A. M., \& Shaw, T. (1996). Treating Sexual Offenders Who Deny Their Guilt: A Pilot Study. Sexual Abuse: A Journal of Research and Treatment, 8(1), 17-23.

[34] Schwaebe, C. (2005). Learning to Pass: Sex Offenders' Strategies for Establishing a Viable Identity in the Prison General Population. International Journal of Offender Therapy and Comparative Criminology, 49(6), 614-625.

[35] Smith, H. P., Kaminski, R. J., Power, J., \& Slade, K. (2019). Self-harming behaviors in prison: a comparison of suicidal processes, self-injurious behaviors, and mixed events. Criminal Justice Studies, 32(3), 264-286.

[36] Ward, T. (2000). Sexual offenders' cognitive distortions as implicit theories. Aggression and Violent Behavior, 5(5), $491-507$.

[37] Ward, T., Polaschek, D. L. L., \& Beech, A. R. (2006). Theories of sexual offending. John Wiley \& Sons 
[38] Webb, R. T., Shaw, J., Stevens, H., Mortensen, P. B., Appleby, L., \& Qin, P. (2012). Suicide Risk Among Violent and Sexual Criminal Offenders. Journal of Interpersonal Violence, 27(17), 3405-3424.

[39] Zgoba, K. M., Sager, W. R., \& Witt, P. H. (2003). Evaluation of New Jersey's Sex Offender Treatment Program at the Adult Diagnostic and Treatment Center: Preliminary Results. The Journal of Psychiatry \& Law, 31(2), 133-164. 